\title{
Assessment of Knowledge and Factors Affecting Sunlight Exposure of Infants among Mothers Attending Governmental Health Facilities in Debre Markos Town, Ethiopia
}

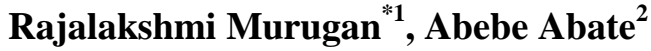 \\ ${ }^{1 *} \mathrm{PhD}$ Scholar in Nursing, Himalayan University, Naharlagun, Itanagar, Arunachal Pradesh, India \\ ${ }^{2}$ Department of Nursing, College of Health Sciences, Debre Markos University, Debre Markos, Ethiopia \\ Correspondence Author \\ Rajalakshmi Murugan, Vaigai Dam, Periyakulam Talk, Theni Disrict, Tamil Nadu, India
}

\begin{abstract}
The main objective of this study was to assess knowldge and factors affecting sunlight exposure of infants among mothers attending governmental health facilities in Debre Markos Town, East Gojjam, Ethiopia, 2015.Cross sectional descriptive study was conducted among mothers attending in under five and immunization clinics of all government health facilities in Debre Markos Town by taking a total sample size of 345. The study result showed that out of 359 respondents identified for the study $96 \%$ (n=345) were responded for the interview. From the total respondents (60\%) of them had poor knowledge about sunlight exposure.The findings in this study revealed mothers had poor knowledge about sunlight exposure. It indicated that mothers need to be educated about the importance of sunlight exposure.
\end{abstract}

Keywords: Knowledge, Sun exposure, Infants, Rickets, Governmental Health Facilities

\section{Introduction}

For centuries, sunlight has been used for therapeutic purposes (heliotherapy), which dates back to ancient Rome and Greece [1]. Studies worldwide identify lack of sun exposure as the main cause of rickets [2]. Rickets is a major public health problem in many countries of the world. In many rich industrialized countries, the prevalence of rickets in the general population diminished after the introduction of dietary supplementation. However, in such countries, vitamin-D deficiency rickets has re-emerged in recent years, particularly among groups with limited exposure to UVB-containing sunshine. Infants at risk of rickets are those whose mothers had poor vitamin $\mathrm{D}$ status during pregnancy and those exclusively breast-fed for a prolonged period with little skin exposure to UVB [3]. Rickets is common in children in Sub-Saharan Africa. Vitamin D deficiency rickets has also common in Ethiopian children [4].

Health education to change maternal behavior to expose infants to sunshine was adopted as the main strategy to combat rickets in Ethiopia. However, the implementation of the strategy has remained inconsistent and health messages lacked focus on factors that influence maternal practice excluding infants from getting adequate sunshine. This was largely because of lack of adequate information on the determinants of this particular risk behavior among Ethiopian mothers [5].

Contrary to general belief, rickets is widely prevalent in many tropical and subtropical regions despite abundant sunshine. The incidence of rickets is particularly high in children who live in crowded houses almost devoid of sunlight [6].

Rickets is common among Ethiopian children. It contributes to infant mortality and morbidity and carries long-term consequences. Factors influencing caregiver behavior of exposing infants to sunshine, a simple preventive strategy, are not fully understood [5].

On the study done in Jimma about $7 \%$ of under-five children were diagnosed to have rickets in paediatric admissions in Jimma Hospital [7].

Another study done on children between 6 and 59 months of age for signs of rickets in Jimma Town, 25(4\%) of children were found to have rickets. The highest rate (11\%) occurred in infants. It is also significantly associated with increased frequency of respiratory infections [8].

Since there is limited research conducted on the title particularly around the study area, the study is intended primarily to assess mothers' knowledge and factors affecting their knowledge about sunlight exposure of their infants.

\section{Objectives}

\subsection{General objective}

To assess knowledge and factors affecting sunlight exposure of infants among mothers attending governmental health facilities in Debre Markos Town, East Gojjam, Ethiopia, 2015. 


\section{International Journal of Science and Research (IJSR) \\ ISSN (Online): 2319-7064 \\ Index Copernicus Value (2013): 6.14 | Impact Factor (2014): 5.611}

\section{$2.2 \quad$ Specific objectives}

- To assess level of mothers' knowledge about sunlight exposure of their infants.

- To identify factors affecting knowledge of mothers about sunlight exposure.

\section{Methods and Materials}

\subsection{Study area and period}

- The study was conducted in all governmental health facilities in Debre Markos Town, East Gojjam, Ethiopia.

\subsection{Study design}

- A cross-sectional institutional based study was conducted.

\section{Source population}

All mothers having children and attending in under five and immunization clinics of all governmental health facilities in Debre Markos Town.

\subsection{Study population}

Mothers with infants attending in under five and immunization clinics of each governmental health facilities at the time of data collection and who fulfill the inclusion criteria.

\subsection{Inclusion criteria}

- Mothers with infants who was attending in under five and immunization clinics of each governmental health facilities in Debre Markos town.

- Those mothers with infants who were volunteer to participate in the study

\subsection{Exclusion criteria}

- Mothers with infants who were not mentally and physically capable of being responded.

\subsection{Sample size determination}

A total of 345 mothers were participated in the study.

\subsection{Sampling procedure}

All governmental health facilities were included in the study. Overall sample was taken proportionally from all governmental health facilities. Each study participants was selected using systematic sampling technique.

\subsection{Data collection instrument}

A structured interviewer administered questionnaire adapted from a study done in Jimma [9] and Turkey [32].And it was modified according to Ethiopian context.

\subsection{Data collection procedure}

Before going to the data collection, pretest was done on $5 \%$ of similar mothers. Data were collected through face to face interview method. Five diploma nurses and two Degree nurses were participated as data collectors and supervisors respectively. All data collectors and supervisor were trained for two days on their responsibilities for describing the purpose of the study, how to collect the data and telling clients the importance of honest and genuine reply towards the questions. The principal investigator and supervisors strictly follow the overall activities of the data collection on daily base to ensure the completeness of questionnaire and to give further clarification.

\subsection{Data quality assurance}

Tool was given to expertise to check content validity and accuracy. Questionnaire prepared in English version and translated in to Amharic and back to English to check its consistency. After the pretest based on the response the questionnaire was modified. Data collection was carried out by trained nurses from other units of the health facilities. The collected data were checked by the supervisor daily for completeness and finally the principal investigator monitored the overall quality of data collection.

\subsection{Independent variables}

- Socio-demographic factors (age, religion, ethnicity, marital status, educational status, occupation)

- Mothers belief (sickness, evil eye, cold, pneumonia)

\subsection{Dependent variables}

Knowledge about sunlight exposure

\subsection{Data analysis procedure}

Data were entered in to Epi Data version 3.1 and exported and analyzed using SPSS Software version 20. Mean, Standard deviation, frequencies, percents and odds ratio were calculated. Binary and multiple logistic regression analysis were determined to assess the association between independent and dependent variables. The strength of statistical association was measured by odds ratio and 95\% confidence intervals and statistical significance was considered at $\mathrm{P}<0.05$.

\subsection{Ethical consideration}

Ethical clearance was obtained from institutional review board of Department of Nursing and Midwifery, College of Health sciences, Addis Ababa University. Permission letter was obtained from woreda health office to all governmental health facilities for their cooperation to conduct the study in the health facilities. Each study participant was adequately informed about the purpose, method and anticipated benefit and risk of the study and the right to withdraw from the study any time by their data collectors. Oral Informed consent was obtained from each study participants. 


\section{International Journal of Science and Research (IJSR) \\ ISSN (Online): 2319-7064 \\ Index Copernicus Value (2013): 6.14 | Impact Factor (2014): 5.611}

\subsection{Operational definitions}

- Good Knowledge- Mothers responded to knowledge questions and scored above 4 median value.

- Poor knowledge- Mothers responded to practice questions and scored 4 and below 4 median value.

\section{Results and Discussion}

\subsection{Socio-demographic Characteristics of respondents}

Out of 359 mothers identified for the study, 345(96\%) responded to the interview. From those respondents 156(45.2\%) were between age 21 and 26 years. The mean age of the mothers were $26.9( \pm 5.3)$ years and mean ages of the children were $4.7(( \pm 3.2)$ months. About $(96.5 \%)$ of the participants were Orthodox in religion and 339 (98.3\%) were Amhara in ethnicity. Majority 329 (95.4\%) of mothers were married and 86(24.9\%) of mothers had diploma and above in their educational status. And $167(48.4 \%)$ of the respondents were housewives and 202(58.6\%) of mothers had household family of 1-3 (Table1).

Table 1: Distribution of socio-demographic characteristics of mothers’ in Debre Markos Town, Ethiopia, 2015 (N=345).

\begin{tabular}{|c|c|c|}
\hline Variable Name & Frequency & Percent (\%) \\
\hline \multicolumn{3}{|l|}{ Mother's age } \\
\hline $15-20$ & 29 & 8.4 \\
\hline $21-26$ & 156 & 45.2 \\
\hline $27-32$ & 102 & 29.6 \\
\hline $33+$ & 58 & 16.8 \\
\hline Total & 345 & 100 \\
\hline \multicolumn{3}{|l|}{ Marital status } \\
\hline Single & 7 & 2 \\
\hline Married & 329 & 95.4 \\
\hline Divorced & 6 & 1.7 \\
\hline Widowed & 3 & 0.9 \\
\hline Total & 345 & 100 \\
\hline \multicolumn{3}{|l|}{ Mother's educational status } \\
\hline unable to read and write & 38 & 11 \\
\hline able to read and write & 55 & 15.9 \\
\hline grade $1-6$ & 86 & 24.9 \\
\hline grade $7-10$ & 67 & 19.5 \\
\hline grade $11-12$ & 13 & 3.8 \\
\hline Degree and above & 86 & 24.9 \\
\hline Total & 345 & 100 \\
\hline \multicolumn{3}{|l|}{ Mother's occupation } \\
\hline Student & 12 & 3.5 \\
\hline House wife & 167 & 48.4 \\
\hline Government employee & 90 & 26.1 \\
\hline Private employee & 23 & 6.7 \\
\hline Daily labourer & 14 & 4.1 \\
\hline Merchant & 31 & 9 \\
\hline Others & 8 & 2.3 \\
\hline Total & 345 & 100 \\
\hline \multicolumn{3}{|l|}{ Family size } \\
\hline $1-3$ & 204 & 59.1 \\
\hline $4-6$ & 135 & 39.1 \\
\hline$>6$ & 6 & 1.7 \\
\hline Total & 345 & 100 \\
\hline \multicolumn{3}{|l|}{ Husband's educational status } \\
\hline unable to read and write & 23 & 6.7 \\
\hline able to read and write & 42 & 12.2 \\
\hline grade $1-6$ & 9 & 2.6 \\
\hline grade $7-10$ & 66 & 19.1 \\
\hline grade $11-12$ & 63 & 18.3 \\
\hline Degree and above & 126 & 36.5 \\
\hline Missing & 16 & 4.6 \\
\hline Total & 345 & 100 \\
\hline
\end{tabular}

\subsection{Mothers' source of information about sunlight exposure of infants}

Out of the total 345 respondents, 297 (86.1\%) of the mothers had information (knowledge) about sunlight exposure of infants and majority 189 (63.6\%) of mothers got this information from neighbors and 127(42.8\%) from midwife/nurse. 


\section{International Journal of Science and Research (IJSR) \\ ISSN (Online): 2319-7064}

Index Copernicus Value (2013): 6.14 | Impact Factor (2014): 5.611

\subsection{Knowledge of respondents about sunlight exposure}

Regarding benefit of sunlight exposure 273 (91.9\%) of mothers said sunlight exposure was beneficial for infants and from these 192 (70.3\%) mention sunlight exposure was useful to strength bone, 138(50.5\%) mention sunlight exposure was useful to strength body and 100 (36.6\%) mention sunlight exposure was useful for vitamin D production, sun strengthen teeth and sun warm a body were also indicated by the respondents as a benefit of sunlight exposure.

Regarding to harmful effect of sunlight exposure $50(14.5 \%)$ said sunlight exposure had harmful effect for the infant and most mentioned harmful effect of sunlight exposure was 39(11.3\%) skin cancer. About time of sunlight exposure $297(100 \%)$ of mothers said good time to expose infants on sunlight was at the morning (Table 2).

Table 2: Knowledge of mothers' about sunlight exposure of their infants in Debre Markos Town, Ethiopia, 2015

\begin{tabular}{|c|c|c|c|}
\hline Variable name & Attributes & Frequency & Percent \\
\hline \multirow{3}{*}{ Mentioned sunlight exposure was beneficial } & Yes & 273 & 91.9 \\
\hline & No & 24 & 8.1 \\
\hline & Total & 297 & 100 \\
\hline \multirow{3}{*}{ Mentioned strengthen bone as a benefit of sunlight exposure } & Yes & 192 & 70.3 \\
\hline & No & 81 & 29.7 \\
\hline & Total & 273 & 100 \\
\hline \multirow{3}{*}{ Mentioned strengthen teeth as a benefit of sunlight exposure } & Yes & 41 & 15 \\
\hline & No & 232 & 85 \\
\hline & Total & 273 & 100 \\
\hline \multirow{3}{*}{ Mentioned keep child warm as a benefit of sunlight exposure } & Yes & 36 & 13.2 \\
\hline & No & 237 & 86.8 \\
\hline & Total & 273 & 100 \\
\hline \multirow{3}{*}{ Mentioned vitamin D production as a benefit of sunlight exposure } & Yes & 100 & 36.6 \\
\hline & No & 173 & 63.4 \\
\hline & Total & 273 & 100 \\
\hline \multirow{3}{*}{ Mentioned strengthen body as a benefit of sunlight exposure } & Yes & 138 & 50.5 \\
\hline & No & 135 & 49.5 \\
\hline & Total & 273 & 100 \\
\hline \multirow{3}{*}{ Mentioned sunlight exposure had harmful effect } & Yes & 50 & 16.8 \\
\hline & No & 247 & 83.2 \\
\hline & Total & 297 & 100 \\
\hline \multirow{3}{*}{ Mentioned skin cancer was a harmful effect of sunlight exposure } & Yes & 39 & 78 \\
\hline & No & 11 & 22 \\
\hline & Total & 50 & 100 \\
\hline \multirow{3}{*}{ Mentioned blindness was a harmful effect of sunlight exposure } & Yes & 37 & 74 \\
\hline & No & 13 & 26 \\
\hline & Total & 50 & 100 \\
\hline \multirow{3}{*}{$\begin{array}{c}\text { Mentioned sterility was a harmful effect of sunlight } \\
\text { Exposure }\end{array}$} & Yes & 1 & 2 \\
\hline & No & 49 & 98 \\
\hline & Total & 50 & 100 \\
\hline
\end{tabular}

\subsection{Mothers' knowledge level about sunlight exposure of infants}

Based on the above knowledge questions median value was calculated and it was 4, out of 345 respondents $207(60 \%)$ of respondents scored less than or equal to 4 . Therefore, based on the operational definition $60 \%$ of mothers had poor knowledge about sunlight exposure of infants.

\subsection{Factors affecting knowledge of mothers on sunlight exposure of infants}

In the bivariate analysis significant association was observed between maternal age and knowledge of mothers, mothers with the age group of above 33 years were 8.67 times more likely knowledgeable than mothers with age group of $15-20$ years $(\mathrm{COR}=8.67,95 \% \mathrm{CI}=2.36$, 31.84).
The educational status of mothers also associated with knowledge, mothers who have diploma and above were 3.24 times more knowledgeable than mothers who were unable to read and write. $(\mathrm{COR}=3.24(95 \% \mathrm{CI}=1.46,7.22))$. Family size of 4-6 were 3.88 times more knowledgeable than family size of $1-3(\mathrm{COR}=3.88(95 \% \mathrm{CI}=2.45,6.17))$.

Mothers who have diploma and above husband educational status were 2.92 times more likely to have knowledge than mothers who have husbands unable to read and write $(\mathrm{COR}=2.92(95 \% \mathrm{CI}=1.08,7.90)$.

Variables that had p-value less than 0.2 in the bivariate analysis taken into multivariate analysis and the significant association between maternal age, maternal education, family size, husband educational status and knowledge about sunlight exposure was retained in the multivariate analysis (Table 3). 


\section{International Journal of Science and Research (IJSR) ISSN (Online): 2319-7064 \\ Index Copernicus Value (2013): 6.14 | Impact Factor (2014): 5.611}

Table 3: Association of socio-demographic variables with knowledge of mothers on sunlight exposure of infants in Debre

Markos Town, Ethiopia, 2015

\begin{tabular}{|c|c|c|c|c|c|c|}
\hline \multirow{2}{*}{ Variables } & \multicolumn{6}{|c|}{ Knowledge of mothers about sunlight exposure } \\
\hline & Poor & Good & p-value & COR & P-value & $A O R$ \\
\hline $\begin{array}{c}\text { Mothers' age } \\
15-20 \\
21-26 \\
27-32 \\
33+\end{array}$ & $\begin{array}{c}26(7.5 \%) \\
110(31.9 \%) \\
42(12.2 \%) \\
29(8.4 \%)\end{array}$ & $\begin{array}{c}3(0.9 \%) \\
46(13.3 \%) \\
60(17.4 \%) \\
29(8.4 \%)\end{array}$ & $\begin{array}{l}0.00 \\
\mathbf{0 . 0 4} \\
\mathbf{0 . 0 0} \\
\mathbf{0 . 0 0}\end{array}$ & $\begin{array}{c}1 \\
3.62(1.04,12.57) \\
12.38(3.52,43.58) \\
8.67(2.36,31.84)\end{array}$ & $\begin{array}{l}0.05 \\
0.11 \\
\mathbf{0 . 0 1} \\
\mathbf{0 . 0 3}\end{array}$ & $\begin{array}{c}1 \\
2.93(0.77,11.15) \\
5.71(1.43,22.89) \\
4.93(1.16,21.01)\end{array}$ \\
\hline $\begin{array}{c}\text { Marital status } \\
\text { Single } \\
\text { Married } \\
\text { Divorced } \\
\text { Widowed } \\
\end{array}$ & $\begin{array}{c}5(1.4 \%) \\
195(56.5 \%) \\
4(1.2 \%) \\
3(0.9) \\
\end{array}$ & $\begin{array}{c}2(0.6 \%) \\
134(38.8 \%) \\
2(0.6 \%) \\
0(0.0 \%) \\
\end{array}$ & $\begin{array}{l}0.91 \\
0.52 \\
0.85 \\
0.99 \\
\end{array}$ & $\begin{array}{c}1 \\
1.71(0.32,8.99) \\
1.25(1.85,1.25) \\
0.00(0.00) \\
\end{array}$ & & \\
\hline $\begin{array}{l}\text { Mother's educational status } \\
\text { unable to read and write } \\
\text { able to read and write } \\
\text { grade } 1-6 \\
\text { grade } 7-10 \\
\text { grade } 11-12 \\
\text { Degree and above }\end{array}$ & $\begin{array}{c}25(7.2 \%) \\
29(8.4 \%) \\
70(20.3 \%) \\
45(13 \%) \\
6(1.7 \%) \\
32(9.3 \%)\end{array}$ & $\begin{array}{c}13(3.8 \%) \\
26(7.5 \%) \\
16(4.6 \%) \\
22(6.4 \%) \\
7(2 \%) \\
54(15.7 \%)\end{array}$ & $\begin{array}{c}0.00 \\
0.21 \\
0.06 \\
0.89 \\
0.22 \\
\mathbf{0 . 0 0 4}\end{array}$ & $\begin{array}{c}1 \\
1.73(0.73,0.4 .05) \\
0.44(0.19,1.04) \\
0.94(0.41,2.18) \\
2.24(0.62,8.07) \\
3.24(1.46,7.22)\end{array}$ & $\begin{array}{c}0.05 \\
0.68 \\
0.65 .0 .26 \\
0.24 \\
\mathbf{0 . 0 3}\end{array}$ & $\begin{array}{c}1 \\
1.26(0.41,3.90) \\
0.79(0.27,2.24) \\
1.83(0.63,5.32) \\
2.47(0.55,11.08) \\
3.16(1.12,8.87)\end{array}$ \\
\hline $\begin{array}{c}\text { Mother's occupation } \\
\text { Student } \\
\text { House wife } \\
\text { Government employee } \\
\text { Private employee } \\
\text { Daily labourer } \\
\text { Merchant } \\
\text { Others } \\
\end{array}$ & $\begin{array}{c}7(2 \%) \\
110(31.9 \%) \\
36(10.4 \%) \\
18(5.2 \%) \\
10(2.9 \%) \\
19(5.5 \%) \\
7(2 \%) \\
\end{array}$ & $\begin{array}{c}5(1.4 \%) \\
57(16.5 \%) \\
54(15.7 \%) \\
5(1.4 \%) \\
4(1.2 \%) \\
12(3.5 \%) \\
1(0.3 \%) \\
\end{array}$ & $\begin{array}{l}0.00 \\
0.60 \\
0.23 \\
0.22 \\
0.49 \\
0.86 \\
0.19\end{array}$ & $\begin{array}{c}1 \\
0.72(0.22,2.39) \\
2.10(0.62,7.13) \\
0.39(0.08,1.77) \\
0.56(0.11,2.86) \\
0.88(0.22,3.43) \\
0.20(0.02,2.18) \\
\end{array}$ & & \\
\hline $\begin{array}{c}\text { Family size } \\
1-3 \\
4-6 \\
>6 \\
\end{array}$ & $\begin{array}{c}147(42.6 \%) \\
55(15.9 \%) \\
5(1.4 \%)\end{array}$ & $\begin{array}{c}55(15.9 \%) \\
80(23.2) \\
3(0.9 \%)\end{array}$ & $\begin{array}{l}0.00 \\
\mathbf{0 . 0 0} \\
0.23 \\
\end{array}$ & $\begin{array}{c}1 \\
3.88(2.45,6.17) \\
2.67(0.52,13.64)\end{array}$ & $\begin{array}{l}0.00 \\
\mathbf{0 . 0 0} \\
0.59 \\
\end{array}$ & $\begin{array}{c}1 \\
2.91(1.59,5.35) \\
1.66(0.26,10.49) \\
\end{array}$ \\
\hline $\begin{array}{l}\text { Husband's education } \\
\text { unable to read and write } \\
\text { able to read and write } \\
\text { grade } 1-6 \\
\text { grade } 7-10 \\
\text { grade } 11-12 \\
\text { Degree and above }\end{array}$ & $\begin{array}{c}17(5.2 \%) \\
20(6.1 \%) \\
8(2.4 \%) \\
55(16.7 \%) \\
33(10 \%) \\
62(18.8 \%)\end{array}$ & $\begin{array}{c}6(1.8 \%) \\
22(6.7 \%) \\
1(0.3 \%) \\
11(3.3 \%) \\
30(9.1 \%) \\
64(19.5 \%)\end{array}$ & $\begin{array}{l}0.00 \\
\mathbf{0 . 0 4} \\
0.37 \\
0.33 \\
0.78 \\
\mathbf{0 . 0 3}\end{array}$ & $\begin{array}{c}1 \\
3.11(1.03,9.46) \\
0.35(0.04,3.45) \\
0.57(0.18,1.76) \\
2.58(0.90,7.39) \\
2.92(1.08,7.90)\end{array}$ & $\begin{array}{l}0.02 \\
\mathbf{0 . 0 4} \\
0.57 \\
0.73 \\
0.07 \\
0.31\end{array}$ & $\begin{array}{c}1 \\
3.89(1.01,14.93) \\
0.48(0.03,6.32) \\
0.80(0.21,2.98) \\
3.08(0.92,10.34) \\
1.87(0.56,6.21)\end{array}$ \\
\hline
\end{tabular}

* Statistically significant at p-value $<0.05$

\section{Discussion}

The aim of this study was to assess knowledge and associated factors of sunlight exposure of infants among mothers attending governmental health facilities in Debre Markos town. Current approach of the Ethiopian government is decreasing child morbidity and mortality. Therefore, knowledge of sunlight exposure is one important aspect in maintaining children's health.

The proportion of respondents who reported that they had the information (knowledge) about sunlight exposure was $86.1 \%$, the same study done in Jimma town showed that $100 \%$ of mothers had information about sunlight exposure [31]. My finding was comparatively lower than the study done in Jimma town; the possible reason for this may be socio demographic and cultural difference.
Out of the total respondents responded to the question does sunlight exposure beneficial, 91.1\% mentioned sunlight exposure was beneficial; it was lower than the study done in Jimma town which was 99.68\% [31]. The reason behind may be due to socio demographic and cultural difference and this finding was higher compared to the study done in Sakarya which was $64.1 \%$ [32]. The possible reason for this may be mothers in Sakarya educated about harmful effect of sunlight exposure rather than benefit of sunlight exposure because they live in a high temperature region and they had fear of skin cancer. Seventy percent of the respondents mentioned the most benefit of sunlight exposure was strengthening bone; this finding was similar to the same study done in Jimma town which was $64.62 \%$ [31].

When mothers asked about harmful effect of sunlight exposure $16.8 \%$ mentioned sunlight exposure had harmful effect, it was lower than the same study done in Sakarya 


\section{International Journal of Science and Research (IJSR) \\ ISSN (Online): 2319-7064 \\ Index Copernicus Value (2013): 6.14 | Impact Factor (2014): 5.611}

which was $64.1 \%$ [32]. The reason behind may be due to Sakarya was found in tropical region in which there was high temperature in this region and due to this mothers may learn about harmful effect of sunlight exposure. The most frequently harmful effect of sunlight exposure mentioned in this study was skin cancer $78 \%$ and it was similar to the same study done in Sakarya which showed $75.9 \%$ [32]. When mothers asked about good time to sunlight exposure of infants, all mothers $100 \%$ mentioned it was in the morning that is similar to the same study done in Jimma town which was $100 \%$ [31].

In the bivariate analysis, for mothers knowledge, significant association was observed between maternal age, mothers educational status, family size, husband educational status and knowledge of mothers with odds ratio of $(\mathrm{COR}=8.7,95 \% \mathrm{CI}=2.4,31.8), \quad(\mathrm{COR}=3.24$, 95\% $\mathrm{CI}=1.46,7.22),(\mathrm{COR}=3.88,95 \% \mathrm{CI}=2.45,6.17)$, (COR=3.11, 95\% CI=1.03, 9.46) respectively. These variables had also significant association with knowledge in multivariate analysis. The other variables: marital status and mothers' occupation had no statistically significant association with knowledge of mothers. And on the study done in Townsville, Australia, maternal age and maternal education had similar association with knowledge [1].

\section{Conclusion}

In this study, about (60\%) of mothers had poor sunlight exposure knowledge. Maternal age, mothers educational status, family size, husband educational status had significant association with mothers' knowledge about sunlight exposure of infants.

\section{Recommendation}

This study finding help health care professionals should create awareness by giving continuous health education program about benefit of sunlight exposure of infants among mothers. Finally, researchers should do further study to identify knowledge, attitude and practice of mothers with qualitative data about sunlight exposure of infants at large scale.

\section{Conflict of Interest}

The authors declare that they have no compete of interest.

\section{Acknowledgment}

Our appreciation extends to Debre Markos University Staffs for their continuous support and assistance throughout our work. We like to thank department of Nursing and midwifery, Addis Ababa University.

We would also like to thank supervisors, data collectors and study participants.

\section{References}

[1] Harrison SL, Buettner PG, MacLennan R. Why do mothers still sun their infants?

[2] J Paediatr Child Health.2002; 35:296-299.
[3] Holick M. Vitamin D deficiency. N Eng J Med 2007, 357, 266-81.

[4] Anthony N, Roger B, Daniel B. Nutritional rickets around the world. Journal of Steroid Biochemistry and Molecular Biology, July 2013; 136: 201-206.

[5] Vitamin D wiki. Review of vitamin D Deficiencies in developing countries. October 2011.

[6] Sileshi L, Catherine D.Behavioral intention and factors influencing intention of Ethiopian mothers to expose infants to sunshine. April, 1999.

[7] Redy V, lamb WH. Nutritional Rickets. In: Stanfield $\mathrm{P}$, Brueton $\mathrm{M}$, Chan M, Parkin M, Waterston T, editors. Diseases of children in the subtropics \& Tropics. $4^{\text {th }}$ ed. Edward Arnold, 1991; 376-379.

[8] Eshetu M. Analysis of paediatric admissions to Jimma Hosptial paediatrics ward: A three year retrospective study. Bulletin of Jimma Institute of Health Sciences 1994; 4:1-11.

[9] Tesfaye G, Afework A, Zerihun T. Rickets and the knowledge and practice of exposure to sunlight in Jimma Town. 1998.

[10] Nihal A, Tuncay M, Pinar T, Suleyman G. Knowledge and behaviour of parents concerning sunning their babies. BMC Pediatrics 2006, 6:27

\section{Authors Profile}

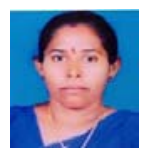

Rajalakshmi Murugan Assistant professor and $\mathrm{PhD}$ Scholar in Nursing, Himalayan University, Naharlagun, Itanagar, Arunachal Pradesh, India. Completed Msc Nursing in the year 1998, Published many research articles in International journals. 23 years experience in teaching and clinical experience, 10 experience as a research guide for Msc students.

Abebe Abate Lecture in Department of Nursing, College of Health Sciences, Debre Markos University, Debre Markos, Ethiopia 